\section{Prematurity at birth and adolescent depressive}

\section{disorder}

\author{
GEORGE C. PATTON, CAROLYN COFFEY, JOHN B. CARLIN, \\ CRAIG A. OLSSON and RUTH MORLEY
}

\begin{abstract}
Summary Association between prematurity/low birthweight and adolescent depressive disorder studied using a case-control design within a prospective cohort study of 2032 adolescents. Odds for depressive disorder were II-fold (95\% Cl 2-62) higher for the premature/low-birthweight participants after regression adjustment for major confounding factors. For premature/lowbirthweight females, cumulative rates of depressive disorder over 30 months were 15.2\% (95\% Cl II.I-20.5) v. I.8\% (95\% Cl I.6-2.I) in those with normal deliveries. Physiological adaptations in utero before full term may be implicated causally in some cases of depression in adolescence.
\end{abstract}

\section{Declaration of interest None.}

Prematurity and low birthweight have been linked to IQ, attention deficit disorder and emotional problems in children (Bhutta $e t$ $a l, 2002)$. Two recent studies have suggested an association between birthweight and psychological distress in early adulthood (Cheung, 2002) and middle age (Cheung et al, 2002). The present report addresses the relationship between intra-uterine growth, as measured by prematurity and low birthweight, and depressive disorder in late adolescence, a period of peak incidence for first episodes. It also tests the mediating role of three established risk factors: preexisting symptoms of depression and anxiety, negative life events and parental bonding.

\section{METHOD}

Sampling, assessment and data analytical procedures for the state-wide case-control study are described elsewhere (Patton et al, 2003). Between August 1992 and July 1995 we conducted a six-wave cohort study of adolescent health in Victoria, Australia.
The current nested study took place between waves 2 and 6 . The nested study was open to participants with at least one previous data wave, resulting in 6653 available observations. The mean age (s.d.) at wave 2 was $15.0(0.4)$ and at wave 6 it was $17.4(0.4)$ years.

The computerised revised Clinical Interview Schedule (CIS-R) identified putative episodes of ICD-10 (World Health Organization, 1992) depressive disorder in the cohort study (Lewis \& Pelosi, 1992) for a second-phase face-to-face interview. A sample of CIS-R non-cases was also selected at random from participants in the same school in a 2:1 ratio to cases.

Blinded face-to-face interview included:

(a) Depression and hypomania modules of the Composite International Diagnostic Interview (CIDI, Core Version 1.1; Robins et al, 1988) were used to generate lifetime ICD-10 diagnoses for affective disorder. The CIDI cases were excluded from reselection at later study waves. Two diagnostic categories for depressive disorder were defined: all cases diagnosed by the CIDI and a second category of 'stable' depressive disorder that concurrently fulfilled criteria on both the CIS-R and the CIDI.

(b) Recent life events measured using an adapted List of Threatening Experiences Questionnaire (Brugha et al, 1985).

(c) The Parental Bonding Instrument (PBI; Parker et al, 1979) was administered immediately prior to the CIDI.

The CIS-R data, from 6 months earlier, provided an index of pre-existing depressive and anxiety symptoms.

Parental telephone interviews (blinded) took place after completion of wave 6 of the cohort. All parents of participants diagnosed with depressive disorder were approached, together with the parents of two controls drawn from the equivalent school and wave. Maternal interviews were completed in $66(73 \%)$ of the CIDI cases and $150(81 \%)$ of the controls. Paternal interviews were completed in $53(62 \%)$ of the cases and $130(74 \%)$ of the controls. The parental interview consisted of:

(a) A diagnostic interview of each parent using the CIDI, with parental disorder defined as either parent having ever experienced a depressive episode.

(b) Gestational age and birthweight were based on maternal report (Ison et al, 1997). When mothers were unavailable (dead or uncontactable) this information was collected from fathers (5) or adoptive parents (1). Birthweight of $<2.5 \mathrm{~kg}$ was categorised as low birthweight and delivery $\geqslant 3$ weeks prior to term was categorised as premature.

Associations with depressive disorder were examined using conditional logistic regression (Stata, release 7.0), with matching defined by school and wave of selection. Inverse probability weighting was used to estimate the cumulative prevalence of depressive disorder, with $95 \%$ CIs obtained using Stata's survey estimation procedures.

\section{RESULTS}

The cumulative rate of stable depressive disorder (CIS-R and CIDI) over 30 months was $2.1 \%(95 \%$ CI $1.8-2.5)$ in females and $0.33 \% \quad(95 \%$ CI $0.19-0.54)$ in males. Cumulative rates of stable depressive disorder in those born at term and those of birthweight $\geqslant 2500 \mathrm{~g}$ were low: $0.25 \%$ (95\% CI $0.13-0.5)$ in males and $1.8 \%$ (95\% CI 1.6-2.1) in females. Rates were $1.0 \%$ (95\% CI 0.8-1.3) in premature lowbirthweight males and substantially higher at $15.2 \%$ (95\% CI $11.1-20.5)$ in premature low-birthweight females.

Matched pairs or triplets for CIDIdefined depressive disorder (i.e. at least one case and one control from a specific school and wave of selection) were available with complete (parental response) data for 63 cases and 112 controls. For stable depressive disorder, 49 cases were matched with 102 controls. On bivariate analysis, prematurity and low birthweight were associated with approximately sixfold $(\mathrm{OR}=$ 5.7 ; $95 \%$ CI 1.4-2.3) and approximately threefold $\quad(\mathrm{OR}=2.9 ; \quad 95 \%$ CI $0.6-1.4)$ increases in the odds of CIDI-defined depressive disorder, respectively.

The potential mediating roles of adverse parenting, heightened responses to social adversity and high levels of preexisting symptoms were considered in further conditional logistic regression 
models (Table 1). The baseline odds ratio after adjustment for parental education, parental separation, maternal age at birth, maternal smoking in pregnancy, serious illness in the first year of life and parental depressive disorder suggested that either prematurity or low birthweight increased the odds for depressive disorder by $>11$ fold. Both low maternal care and high control were independently associated with depressive disorder but adjustment did not markedly reduce the association with prematurity/low birthweight. Adjustment for negative life events reduced the association with depressive disorder but the clearest reduction in association occurred with the addition of pre-existing depressive and anxiety symptoms to the model. Models using stable depression as the outcome produced similar findings.

\section{DISCUSSION}

Prematurity and low birthweight were associated with a substantially higher rate of depressive disorder in adolescence. After adjustment for potential confounders, the odds for depressive disorder were elevated by $>11$-fold in adolescents born premature or of low birthweight. For females, rates of stable disorder in those born premature or with low birthweight prevalence estimates were $15 \%$, compared with $<2 \%$ in those with normal deliveries.

Poor maternal bonding through childhood did not appear to be a mechanism for the association between prematurity and depressive disorder. However, adjustment of regression models for pre-existing depressive and anxiety symptoms and
GEORGE C. PATTON, MD, FRANCP, CAROLYN COFFEY, MSc, JOHN B. CARLIN, PhD, CRAIG A. OLSSON, $\mathrm{PhD}$, Murdoch Children's Research Institute; RUTH MORLEY, PhD, Department of Paediatrics, University of Melbourne, Australia

Correspondence: Professor George Patton, Centre for Adolescent Health, Murdoch Children's Research Institute, 2 Gatehouse Street, Parkville 3052, Victoria, Australia. E-mail: george.patton@rch.org.au

(First received 30 June 2003, final revision 17 November 2003, accepted I5 December 2003) recent negative life events did reduce the association, suggesting that a heightened sensitivity to social adversity might play a role in depressive disorder in this group.

Foetal genotype, maternal physiology and placental function may affect early brain development through nutritional and hormonal mechanisms (Leon, 2001). For those born prematurely, perinatal stress and suboptimal nutrition in the early weeks ex utero also play a role. Early physiological adaptation, particularly of the hypothalamic-pituitary-adrenal axis (HPA), to intra-uterine nutritional deficiencies has been one explanation for the links between low birthweight and later cardiovascular and diabetes risks (Phillips et al, 1998). The HPA and hypothalamo-pituitarygonadal axes have been implicated in early depression (Patton et al, 1996; Goodyer et al, 2000) and both are affected by low birthweight (Phillips et al, 1998; Ibanez et al, 2000). Thus, a tendency of premature/ low-birthweight subjects to have high circulating glucocorticoids may indicate an early acquired and persisting neurophysiological vulnerability. Such a vulnerability may lower the threshold for depressive and anxiety symptoms in response to adversity and, in time, lead to a more negative appraisal and heightened vulnerability to life events.
Table I Association of prematurity/low birthweight with depressive disorder: (a) after adjustment for background factors; and (b) with further adjustment for parenting style, negative life events and level of earlier depressive and anxiety symptoms as putative mediators

\begin{tabular}{|c|c|c|c|c|}
\hline & $\begin{array}{l}\text { No disorder } \\
(n=I 12)\end{array}$ & $\begin{array}{c}\text { Depressive } \\
\text { disorder }(n=63)\end{array}$ & $\begin{array}{l}\text { (a) Adjusted for } \\
\text { background factors }\end{array}$ & $\begin{array}{l}\text { (b) Complete } \\
\text { model' }\end{array}$ \\
\hline & $n(\%)$ & $n(\%)$ & OR $(95 \% \mathrm{Cl})$ & OR $(95 \% \mathrm{Cl})$ \\
\hline Prematurity/low birthweight & $8(7)$ & $9(14)$ & II.6 (2.2-62) & $6.2(0.8-48)$ \\
\hline \multicolumn{5}{|l|}{ Putative mediators } \\
\hline \multicolumn{5}{|l|}{ Parenting style } \\
\hline Maternal low care & $23(2 I)$ & $30(49)$ & & $2.4(0.7-1 \mathrm{I})$ \\
\hline Maternal high control & $25(23)$ & $32(52)$ & & $2.9(0.7-7.2)$ \\
\hline \multicolumn{5}{|l|}{ Negative life events } \\
\hline Single & $27(24)$ & $30(49)$ & & $3.8(0.6-25)$ \\
\hline Multiple & $25(23)$ & $32(52)$ & & $4.4(0.9-19)$ \\
\hline Previous depression/anxiety & $19(17)$ & $48(77)$ & & $5.9(1.3-36)$ \\
\hline
\end{tabular}

I. All odds ratios adjusted for gender, parental education, parental separation, parental history of depressive disorder, maternal smoking in pregnancy, maternal age at birth and serious illness in the first year of life.

\section{ACKNOWLEDGEMENTS}

National Health and Medical Research Council and Australian Rotary Health Research Fund provided funding for the study.

\section{REFERENCES}

Bhutta, A, T., Cleves, M., Casey, P. H., et al (2002)

Cognitive and behavioral outcome of school-aged children who were born pre-term: a meta-analysis. JAMA, 288, 728-737.

Brugha, T. S., Bebbington, P. E., Tennant, C., et al (1985) The List of Threatening Experiences: a subset of 12 life event categories with considerable long-term contextual threat. Psychological Medicine, 15, 189-194.

Cheung, Y. B. (2002) Early origins and adult correlates of psychosomatic distress. Social Science and Medicine, 55, 937-948.

Cheung, Y. B., Khoo, K. S., Karlberg, J., et al (2002) Association between psychological symptoms in adults and growth in early life: longitudinal follow up study. BMJ, 325, 749-752.

Goodyer, I. M., Herbert, J., Tamplin, A., et al (2000) First-episode major depression in adolescents: affective, cognitive and endocrine characteristics of risk status and predictors of onset. British Journal of Psychiatry, 176, 142-149.

lbanez, L., Potau, N. \& de Zegher, F. (2000) Ovarian hyporesponsiveness to follicle stimulating hormone in adolescent girls born small for gestational age. Journal of Clinical Endocrinology and Metabolism, 85, 2624-2626.

Ison, J. E., Ross, J. A., Pendergrass, T., et al (1997) Medical record validation of maternally reported birth characteristics and pregnancy-related events: a report from the Children's Cancer Group. American Journal of Epidemiology, 145, 58-67.

Leon, D. A. (200I) Getting to grips with fetal programming - aspects of a rapidly evolving agenda. International Journal of Epidemiology, 30, 96-98.

Lewis, G. \& Pelosi, A. J. (1992) The Manual of CIS $-R$. London: Institute of Psychiatry.

Parker, G., Tupling, H. \& Brown, L. B. (1979) A parental bonding instrument. British Journal of Medical Psychology, 5I, I-10.

Patton, G. C., Hibbert, M. E., Carlin, J., et al (1996) Menarche and the onset of depression and anxiety in Victoria, Australia. Journal of Epidemiology and Community Health, 50, 66I-666.

Patton, G. C., Coffey, C., Posterino, M., et al (2003) Life events and early onset depression: cause or consequence? Psychological Medicine, 33, 1203-1210.

Phillips, D. I., Barker, D. J. \& Fall, C. H. D. (1998) Elevated plasma cortisol concentrations: a link between low birth weight and the insulin resistance syndrome? Journal of Clinical Endocrinology and Metabolism, 83, 757-760.

Robins, L., Wing, J., Wittchen, H. U., et al (1988) The Composite International Diagnostic Interview. Archives of General Psychiatry, 45, 1069-1077.

World Health Organization (1992) Tenth Revision of the International Classification of Diseases and Related Health Problems (ICD-10). Geneva: WHO. 